\title{
Effects of Progressive Aerobic Exercise on the Cardiopulmonary Functions of Premenopausal and Postmenopausal Breast Cancer Survivors
}

\author{
Aweto, H.A., Akinbo, S.R.A., Olawale, O.A. \\ Department of Physiotherapy, College of Medicine, University of Lagos, PMB 12003, Idi-Araba, Lagos, Nigeria \\ Correspondence \\ Happiness Anulika Aweto - awetohappiness@gmail.com; haweto@unilag.edu.ng
}

\begin{abstract}
SUMMARY
The incidence rate of breast cancer $(\mathrm{BC})$ continues to rise as the survival rate is still poor in economically developing countries. Therapeutic approaches to improve cardiopulmonary functions and the survival rate of BC survivors are pressing concerns. This study investigated the effects of progressive aerobic exercise on the cardiopulmonary parameters of female BC survivors.

Fifty-eight BC survivors with stage I, II and III breast cancer, referred from the Radiotherapy and Oncology Department of Lagos University Teaching Hospital, participated in the study and 48 of them completed it. The participants were randomly assigned to groups A and B and each group was further subdivided into subgroups 1 (premenopausal women) and 2 (postmenopausal women) based on their menopausal status. Group A underwent aerobic exercise using the treadmill and also had educational and counselling sessions while Group B had only educational and counselling sessions. Selected cardiopulmonary parameters were measured at baseline, $3^{\text {rd }}, 6^{\text {th }}, 9^{\text {th }}$ and $12^{\text {th }}$ weeks of intervention.

Significant improvements were observed in the cardiovascular variables of Groups $A_{(1 \& 2)}$ (Resting systolic blood pressure $(\mathrm{RSBP})\left(\mathrm{A}_{1}: \mathrm{p}=0.00^{*} ; \mathrm{A}_{2}: \mathrm{p}=0.01^{*}\right)$, Resting diastolic blood pressure $(\mathrm{RDBP})\left(\mathrm{A}_{1}: \mathrm{p}=0.03^{*}\right.$; $\left.\mathrm{A}_{2}: \mathrm{p}=0.01 *\right)$, Resting rate pressure product $(\mathrm{RRPP})\left(\mathrm{A}_{1}: \mathrm{p}=0.01 * ; \mathrm{A}_{2}: \mathrm{p}=0.00^{*}\right)$. With the exception of $\mathrm{SaO}_{2}$ $\left(p=0.05^{*}\right)$ of Group $A_{2}$, changes in the pulmonary variables of Groups $A_{(1 \& 2)}$ were not significant. No significant differences were observed in the cardiovascular and pulmonary variables of Groups $B_{(1 \& 2) \text {. }}$.

Aerobic exercise brought about significant therapeutic effects on selected cardiovascular parameters in female BC survivors.
\end{abstract}

KEY WORDS: Aerobic exercise, cardiopulmonary, breast cancer

\section{INTRODUCTION}

Breast cancer (BC) is the commonest cancer affecting women in Nigeria (Adebamowo and Ajayi, 2000). According to global statistics on cancer, $\mathrm{BC}$ is the most frequently diagnosed cancer among women worldwide and the leading cause of cancer death among females, accounting for $23 \%$ of total cancer cases and $14 \%$ of cancer deaths (Jemal et al, 2011). It is a prevalent disease that requires intense and prolonged treatment (Courneya et al, 2003).
The survival rate of individuals with $\mathrm{BC}$ over the past 25 years has improved in the Western countries, resulting in a substantial number of BC survivors (American Cancer Society (ACS), 2012). In the United States of America, BC survivors are estimated to exceed 12 million and $68 \%$ of individuals diagnosed with cancer now live more than 5 years (ACS, 2012). This improvement in survival rate is attributed to early detection of the disease and improvement in cancer care (Jemal et al, 2011). In Nigeria, the survival rate is still very low due to late detection of the disease and 
poor treatment compliance (Adesunkanmi et al, 2006).

Cardiopulmonary capacity may be compromised in BC survivors because of the pathology of the disease, therapeutic regimens, weight gain and inactivity secondary to treatment (Brockstein et al, 2000; Gianni et al, 2001; Courneya et al, 2003; Jones et al, 2010). Weight gain and obesity are common occurrences in women diagnosed with $\mathrm{BC}$ and these adversely increase the risk of cardiovascular disease, hypertension, and diabetes (Calle et al, 1999; Kopelman 2000; Demark-Wahnefried et al, 2001; McInnes and Knobf, 2001). It was observed that cardiopulmonary fitness was approximately $30 \%$ below that of age-matched sedentary healthy women up to three years following the completion of adjuvant therapy (Jones et al, 2007). The precise causes of poor cardiopulmonary fitness are not known but are probably a consequence of direct cytotoxic therapy-associated injury to the cardiovascular system together with lifestyle perturbations (e.g., deconditioning and weight gain) (Jones et al, 2010). This reduction in cardiopulmonary capacity may lead to reductions in QoL and premature death (Courneya et al, 2003). Emerging research evidence indicates that poor cardiopulmonary fitness may be of central importance for certain adverse late effects of the disease, including impaired left ventricular ejection fraction, elevated cardiovascular disease (CVD) risk profile, poor QoL, and fatigue following the completion of adjuvant therapy for operable BC (Jones et al, 2007; Herrero et al, 2006).

Therapeutic exercise has consistently been identified as a central element of rehabilitation for many chronic diseases and has been successful in improving QoL and reducing allcause mortality (McNeely et al, 2006). Observational evidence suggests that moderate-intensity levels of aerobic exercise may reduce the risk of death from $\mathrm{BC}$ and therefore may prove to be a valuable intervention to improve overall survival (Holmes et al, 2005). Some studies from Western countries reported that moderate-intensity aerobic training had significant improvement in the cardiopulmonary parameters of BC survivors (Burnham and Wilcox, 2002; Drouin, 2002; Courneya et al, 2003; Crowley, 2003) while Segal et al (2001) reported that a low-intensity aerobic exercise programme had no effect on aerobic fitness $\left(\mathrm{VO}_{2}\right.$ peak) of $\mathrm{BC}$ patients receiving chemotherapy. There is a dearth of knowledge on the effects of therapeutic exercises on the cardiopulmonary functions of BC survivors in Nigeria. Hence, this study was designed to investigate the effects of progressive aerobic exercise on the cardiovascular and pulmonary functions of premenopausal and postmenopausal BC survivors.

\section{METHODS}

\section{Research Design and Participants}

This study was conducted in Lagos, Nigeria from 2012 to 2014. Fifty-eight (58) premenopausal and postmenopausal BC survivors with stage I, II and III breast cancer were recruited for the study through referrals by physicians from the Radiotherapy and Oncology Department of Lagos University Teaching Hospital (LUTH), Lagos, Nigeria. They were screened for eligibility based on the inclusion and exclusion criteria of the study. Breast cancer survivors with severe orthopaedic and neurologic conditions, severe cardiopulmonary pathologies, and contraindications to exercise as well as those that were involved in routine exercises during the previous six months were excluded. Four (4) were not eligible and therefore were excluded. The remaining 54 eligible subjects were randomly assigned to two groups (A and B). Each of the groups was further subdivided into subgroup 1 and 2 based on the subjects' menopausal status. The randomization was done using computer-generated numbers.

Forty-eight (48) subjects completed the study, while 6 subjects withdrew for reasons such as transportation problems, inability to stay in the Lagos for the 12 weeks duration of the study as well as exacerbation of side effects of radiotherapy / chemotherapy (figure 1). Their ages ranged from 30 to 74 years. Written informed consent was obtained from all the subjects prior to participation. Ethical approval was obtained prior to the study from the Health Research and Ethics Committee of the Lagos University Teaching Hospital, Idi-Araba, Lagos.

\section{Procedure}

Group A underwent moderate-intensity aerobic exercise using the treadmill while Group B (control group) had no therapeutic exercise intervention but had group educational and counselling sessions (for all subjects) for 30 minutes, once every week. Baseline measurements of all the selected cardiopulmonary outcome parameters for the subjects were taken after a rest period of 15 minutes prior to the intervention (Andersen et al, 2010). Resting systolic blood pressure (RSBP) and resting diastolic blood pressure (RDBP) were measured with a mercury sphygmomanometer and a stethoscope in sitting position. 


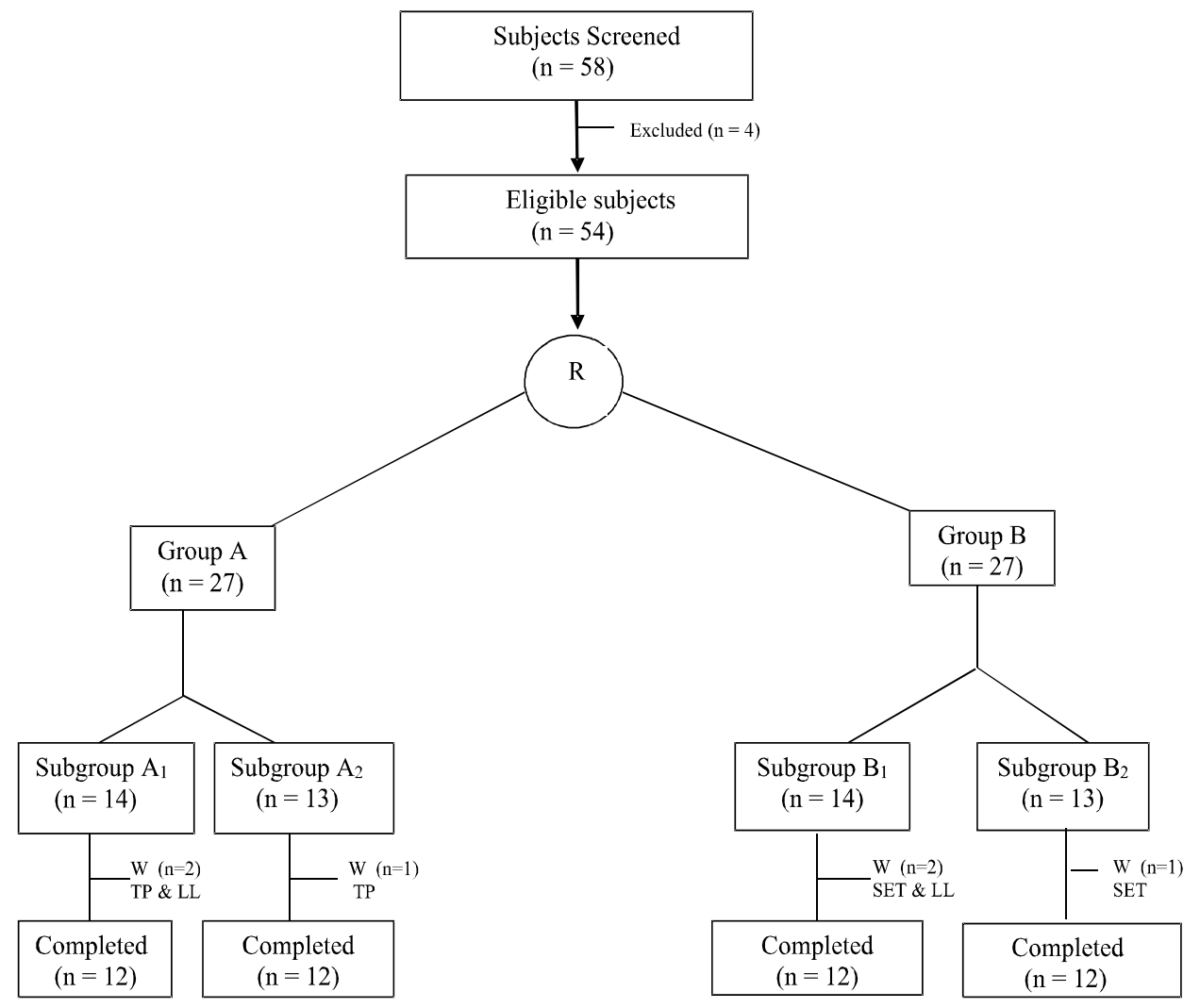

Figure 1. Flow chart showing the recruitment and randomization of subjects into groups. $\mathrm{R}=$ Randomization. Group $\mathrm{A}=$ Aerobic exercise group, Group B = Control group, Subgroup $1=$ Premenopausal BC survivors, Subgroup $2=$ Postmenopausal BC survivors, $\mathrm{W}=$ Withdrawal, $\mathrm{TP}=$ Transport Problems, SET $=$ Side Effects of Treatment exacerbated, LL=Left Lagos during the 12 weeks of study.

Resting heart rate (HR@rest) was measured with a stethoscope, $\mathrm{SaO}_{2}$ with a pulse oximeter (unit) and FVC with a hand-held micro spirometer. Resting rate pressure product (RRPP) is the product of RSBP and HR@rest while $\mathrm{VO}_{2} \max$ was calculated with the formula:

$$
\mathrm{VO}_{2} \max =15 \frac{H R_{\text {max }}}{H R_{\text {rest }}}
$$

(Uth et al, 2005)

Aerobic exercise at moderate intensity for subjects in group A was the equivalent of their target heart rate (THR) and was calculated using the Karvonen formula:

THR =0.6 (MHR - HR@rest) + HR@rest (Tanaka et al, 2001).

On the appointment days, the vital signs of subjects in group A were taken after a rest period of 15 minutes. This was followed by a 5-minute warm-up exercise before aerobic exercise on the treadmill and ended with a 5-minute cool down exercise. Aerobic exercise on the treadmill was for 15 minutes for the first 3 weeks and systematically increased by 5 minutes every 3 weeks (Courneya et al,
2003). Exercise frequency was 3 days a week and measurements of all the selected cardiopulmonary outcome parameters were taken for all the subjects at the end of the $3^{\text {rd }}, 6^{\text {th }}, 9^{\text {th }}$ and $12^{\text {th }}$ weeks.

\section{Data Analysis}

Data was analysed using descriptive statistics of mean and standard deviation. Results were illustrated in tables. The Statistical Package for Social Sciences (SPSS) version 20.0 was used to analyse data. Repetitive analysis of variance (ANOVA) was also used to determine the statistical significance of the cardiovascular and pulmonary variables across the baseline, end of $3^{\text {rd }}, 6^{\text {th }}, 9^{\text {th }}$ and $12^{\text {th }}$ weeks for each group. The paired $t$ test was used to compare the baseline and end of $12^{\text {th }}$ week mean values of cardiovascular and pulmonary variables within groups. The independent $t$ test was used to compare the changes in the selected variables of premenopausal BC survivors with those of postmenopausal BC survivors at the end of the $12^{\text {th }}$ week. Significant level was set at $\mathrm{p} \leq 0.05$. 


\section{RESULTS}

Following 12 weeks of study, repetitive ANOVA of data taken at the end of $3^{\text {rd }}, 6^{\text {th }}, 9^{\text {th }}$ and $12^{\text {th }}$ weeks showed that there were statistically significant improvements in the cardiovascular variables of subjects in Group $A_{1}-$ RSBP ( $p$ $\left.=0.00^{*}\right), \operatorname{RRPP}\left(\mathrm{p}=0.05^{*}\right)-$ while there were no statistically significant improvements in the pulmonary variables. Post-hoc analysis showed that significant changes in RSBP occurred between the baseline and the $6^{\text {th }}$ week, baseline and $9^{\text {th }}$ week and baseline and $12^{\text {th }}$ week. Significant change in RRPP occurred between baseline and $12^{\text {th }}$ week (table 1 ). There were also statistically significant improvements in the cardiovascular variables of subjects in Group $\mathrm{A}_{2}-\operatorname{RSBP}(\mathrm{p}=0.02 *), \operatorname{RDBP}(\mathrm{p}=0.00 *)$, RRPP $(\mathrm{p}=0.04 *)$ - while there were no statistically significant improvements in the pulmonary variables. Post-hoc analysis shows that the significant changes in RSBP and RRPP occurred between baseline and the $12^{\text {th }}$ week while significant changes in RDBP occurred between the baseline and the $9^{\text {th }}$ week and between the baseline and the $12^{\text {th }}$ week (table 1). No significant differences were observed in the cardiovascular and pulmonary variables of subjects in Groups B ${ }_{(1 \& 2)}$ (table 2).

Paired $t$-test comparison of changes in cardiovascular variables between pre-treatment (baseline) and posttreatment $\left(12^{\text {th }}\right.$ week) also showed that there were statistically significant improvements in the cardiovascular variables of subjects in Groups $\mathrm{A}_{(1 \& 2)}-\operatorname{RSBP}\left(\mathrm{A}_{1}: \mathrm{p}=\right.$ $\left.0.00^{*} ; \mathrm{A}_{2}: \mathrm{p}=0.01 *\right), \operatorname{RDBP}\left(\mathrm{A}_{1}: \mathrm{p}=0.03^{*} ; \mathrm{A}_{2}: \mathrm{p}=\right.$ $0.01 *), \operatorname{RRPP}\left(\mathrm{A}_{1}: \mathrm{p}=0.01 * ; \mathrm{A}_{2}: \mathrm{p}=0.00^{*}\right)$ while there were no significant differences observed in the cardiovascular variables of subjects in Groups $\mathrm{B}_{(1 \& 2)}$ (table 3). Although some changes were observed in some of the

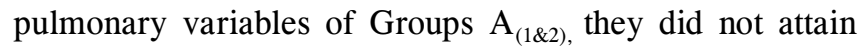
statistically significant improvement levels except the $\mathrm{SaO}_{2}$ ( $\mathrm{p}=0.05^{*}$ ) of Group $\mathrm{A}_{2}$. There were no significant differences observed in the pulmonary variables of subjects in Groups $B_{(1 \& 2)}$ (table 4).

With the exception of RDBP, improvements in the cardiovascular variables of subjects in Group A were more pronounced in the premenopausal BC survivors than in the postmenopausal survivors. There was a significant difference in the mean changes in $\operatorname{RRPP}\left(p=0.05^{*}\right)$ of premenopausal BC survivors compared to postmenopausal $\mathrm{BC}$ survivors. The cumulative mean changes in all the cardiovascular variables were more pronounced in Group A compared with Group B (table 5).

Table 1. Changes in the cardiovascular and pulmonary variables of subjects in Group $A_{1}$ and $A_{2}$

\begin{tabular}{|c|c|c|c|c|c|c|c|c|}
\hline Variables & $\begin{array}{c}\text { Baseline } \\
\text { (A) }\end{array}$ & $\begin{array}{c}3^{\text {rd }} \text { W eek } \\
\text { (B) }\end{array}$ & $\begin{array}{r}6^{\text {th }} \text { W eek } \\
(\mathrm{C})\end{array}$ & $\begin{array}{l}9^{\text {th }} \text { W eek } \\
\text { (D) }\end{array}$ & $\begin{array}{c}12^{\text {th }} \text { W eek } \\
\text { (E) }\end{array}$ & $\mathrm{F}$ & $\begin{array}{l}\mathrm{p}- \\
\text { value }\end{array}$ & Post hoc \\
\hline \multicolumn{9}{|l|}{$\begin{array}{l}\text { GROUP A } \\
\text { CVS }\end{array}$} \\
\hline RSBP (mmHg) & $123.00 \pm 9.07$ & $114.00 \pm 9.91$ & $110.25 \pm 8.51$ & $106.75 \pm 6.04$ & $103.75 \pm 6.27$ & 6.77 & $0.00 *$ & $\begin{array}{l}\mathrm{a} \& \mathrm{c}, \mathrm{a} \& \mathrm{~d} \\
\mathrm{a} \& \mathrm{e}\end{array}$ \\
\hline RDBP (mmHg) & $79.50 \pm 10.68$ & $75.00 \pm 10.80$ & $71.75 \pm 9.04$ & $70.50 \pm 5.93$ & $67.75 \pm 7.89$ & 1.99 & 0.12 & \\
\hline $\begin{array}{l}\text { RRPP } \\
\text { (beats/min/mmHg) }\end{array}$ & $9835.00 \pm 1862.32$ & $8911.00 \pm 1579.69$ & $8563.00 \pm 1623.22$ & $8091.00 \pm 1614.36$ & $7398.00 \pm 1284.78$ & 2.58 & $0.05^{*}$ & a\&e \\
\hline \multicolumn{9}{|l|}{ Pulmonary } \\
\hline $\mathrm{SaO}_{2}(\%)$ & $98.25 \pm 0.71$ & $98.13 \pm 0.83$ & $98.00 \pm 0.53$ & $98.13 \pm 1.13$ & $98.50 \pm 0.53$ & 0.47 & 0.75 & \\
\hline FVC (litres) & $1.79 \pm 0.50$ & $1.95 \pm 0.55$ & $2.04 \pm 0.58$ & $2.09 \pm 0.63$ & $2.25 \pm 0.54$ & 0.73 & 0.58 & \\
\hline $\mathrm{VO}_{2} \max (\mathrm{kg} / \mathrm{ml} / \mathrm{min})$ & $33.89 \pm 4.34$ & $34.93 \pm 4.53$ & $35.34 \pm 5.34$ & $36.38 \pm 6.09$ & $38.42 \pm 4.83$ & 0.92 & 0.46 & \\
\hline \multicolumn{9}{|l|}{$\begin{array}{l}\text { GROUP A } \\
\text { CVS }\end{array}$} \\
\hline RSBP (mmHg) & $125.43 \pm 14.50$ & $114.86 \pm 5.76$ & $113.14 \pm 8.71$ & $112.5 \pm 8.77$ & $108.00 \pm 5.54$ & 3.42 & $0.02 *$ & a\&e \\
\hline RDBP (mmHg) & $84.57 \pm 10.63$ & $79.43 \pm 5.38$ & $76.29 \pm 4.23$ & $72.29 \pm 6.26$ & $70.57 \pm 3.78$ & 5.19 & $0.00 *$ & $\mathrm{a} \& \mathrm{~d}, \mathrm{a} \& \mathrm{e}$ \\
\hline $\begin{array}{l}\text { RRPP } \\
\text { (beats/min/mmHg) }\end{array}$ & $9192.00 \pm 587.24$ & $8761.14 \pm 734.08$ & $8381.71 \pm 726.62$ & $8408.00 \pm 1044.89$ & $7834.29 \pm 787.97$ & 2.83 & $0.04 *$ & a\&e \\
\hline \multicolumn{9}{|l|}{ Pulmonary } \\
\hline $\mathrm{SaO}_{2}(\%)$ & $97.43 \pm 0.53$ & $97.86 \pm 0.38$ & $98.14 \pm 0.69$ & $98.00 \pm 0.00$ & $98.14 \pm 0.69$ & 2.22 & 0.09 & \\
\hline FVC (litres) & $1.70 \pm 0.43$ & $1.90 \pm 0.47$ & $1.93 \pm 0.47$ & $2.01 \pm 0.46$ & $2.17 \pm 0.49$ & 0.93 & 0.46 & \\
\hline $\mathrm{VO}_{2} \max (\mathrm{kg} / \mathrm{ml} / \mathrm{min}$ & $33.35 \pm 2.67$ & $32.21 \pm 3.66$ & $32.76 \pm 2.53$ & $32.20 \pm 1.97$ & $33.35 \pm 2.93$ & 0.25 & 0.91 & \\
\hline
\end{tabular}


Effect of Progressive Aerobic Exercise on Cardiopulmonary Functions of Breast Cancer Survivors

Table 2. Changes in the cardiovascular and pulmonary variables of subjects in Groups $\mathbf{B}_{1}$ and $\mathbf{B}_{2}$

\begin{tabular}{|c|c|c|c|c|c|}
\hline & CVS Variables & $\begin{array}{l}\text { Pre-Rx } \\
\text { (Baseline) }\end{array}$ & $\begin{array}{l}\text { Post-Rx } \\
\left(12^{\text {th }} \text { Week }\right)\end{array}$ & $t$-value & $\mathrm{p}$-value \\
\hline \multicolumn{6}{|c|}{ Premenopausal } \\
\hline \multirow[t]{3}{*}{ GROUP $A_{1}$} & $\operatorname{RSBP}(\mathrm{mmHg})$ & $123.00 \pm 9.07$ & $103.75 \pm 6.27$ & 4.94 & $0.00 *$ \\
\hline & $\mathrm{RDBP}(\mathrm{mmHg})$ & $79.50 \pm 10.68$ & $67.75 \pm 7.89$ & 2.50 & $0.03 *$ \\
\hline & $\mathrm{RRPP}($ beat $/ \mathrm{min} / \mathrm{mmHg}$ ) & $9835.00 \pm 1862.32$ & $7398.00 \pm 1284.78$ & 3.05 & $0.01 *$ \\
\hline \multirow[t]{3}{*}{ GROUP B $B_{1}$} & RSBP(mmHg) & $117.00 \pm 14.70$ & $117.00 \pm 16.73$ & 0.00 & 1.00 \\
\hline & $\mathrm{RDBP}(\mathrm{mmHg})$ & $77.50 \pm 17.08$ & $75.50 \pm 17.31$ & 0.16 & 0.81 \\
\hline & $\mathrm{RRPP}(\mathrm{beat} / \mathrm{min} / \mathrm{mmHg}$ ) & $9848.00 \pm 2862.41$ & $10021.00 \pm 2407.39$ & -0.09 & 0.93 \\
\hline \multicolumn{6}{|c|}{ Postmenopausal } \\
\hline \multirow[t]{3}{*}{ GROUP $\mathrm{A}_{2}$} & $\mathrm{RSBP}(\mathrm{mmHg})$ & $125.43 \pm 14.50$ & $108.00 \pm 5.54$ & 2.97 & $0.01 *$ \\
\hline & $\mathrm{RDBP}(\mathrm{mmHg})$ & $84.57 \pm 10.63$ & $70.57 \pm 3.78$ & 3.28 & $0.01 *$ \\
\hline & $\mathrm{RRPP}(\mathrm{beat} / \mathrm{min} / \mathrm{mmHg}$ ) & $9192.00 \pm 587.24$ & $7834.29 \pm 787.97$ & 3.66 & $0.00 *$ \\
\hline \multirow[t]{3}{*}{ GROUP $B_{2}$} & $\mathrm{RSBP}(\mathrm{mmHg})$ & $133.00 \pm 12.06$ & $125.00 \pm 15.19$ & 0.83 & 0.44 \\
\hline & $\mathrm{RDBP}(\mathrm{mmHg})$ & $89.00 \pm 6.63$ & $82.00 \pm 2.83$ & 1.94 & 0.10 \\
\hline & RRPP(beat $/ \mathrm{min} / \mathrm{mmHg}$ ) & $11515.00 \pm 1356.72$ & $11058.00 \pm 660.87$ & 0.61 & 0.57 \\
\hline
\end{tabular}

Key: $\mathrm{RSBP}=$ Resting Systolic Blood Pressure, $\mathrm{RDBP}=$ Resting Diastolic Blood Pressure, RRPP $=$ Resting Rate Pressure Product, SaO ${ }_{2}$ Arterial Oxyhaemoglobin Saturation, $\mathrm{FVC}=$ Forced Vital Capacity, $\mathrm{VO}_{2} \mathrm{max}=$ Maximal Oxygen Uptake.

Table 3. Comparison of changes in cardiovascular variables between pre-treatment (baseline) and post-treatment $\left(12^{\text {th }}\right.$ week) of the premenopausal and postmenopausal study groups

\begin{tabular}{|c|c|c|c|c|c|c|c|}
\hline Variables & $\begin{array}{c}\text { Baseline } \\
\text { (A) }\end{array}$ & $\begin{array}{c}3^{\text {rd }} \text { W eek } \\
\text { (B) }\end{array}$ & $\begin{array}{r}6^{\text {th }} \text { W eek } \\
(\mathrm{C})\end{array}$ & $\begin{array}{r}9^{\text {th }} \text { W eek } \\
\text { (D) }\end{array}$ & $\begin{array}{c}12^{\text {th }} \text { W eek } \\
\text { (E) }\end{array}$ & $\mathrm{F}$ & p-value \\
\hline \multicolumn{8}{|l|}{ GROUP B $_{1}$} \\
\hline \multicolumn{8}{|l|}{ CVS } \\
\hline RSBP (mmHg) & $117.00 \pm 15.87$ & $117.00 \pm 22.24$ & $115.50 \pm 17.23$ & $112.50 \pm 16.36$ & $117.00 \pm 18.07$ & 0.05 & 1.00 \\
\hline RDBP (mmHg) & $77.50 \pm 17.08$ & $76.50 \pm 16.52$ & $76.00 \pm 19.93$ & $73.00 \pm 16.37$ & $75.50 \pm 17.31$ & 0.04 & 1.00 \\
\hline $\mathrm{RRPP}$ (beats/min/mmHg) & $9848.00 \pm 2862.41$ & $10201.00 \pm 2930.07$ & $9448.00 \pm 1180.59$ & $10244.00 \pm 1707.45$ & $10021.00 \pm 2407.39$ & 0.08 & 0.99 \\
\hline \multicolumn{8}{|l|}{ Pulmonary } \\
\hline $\mathrm{SaO}_{2}(\%)$ & $98.75 \pm 0.50$ & $98.00 \pm 0.00$ & $98.00 \pm 0.00$ & $98.25 \pm 0.50$ & $98.00 \pm 0.00$ & 0.25 & 0.89 \\
\hline FVC (litres) & $1.88 \pm 0.49$ & $1.98 \pm 0.46$ & $1.99 \pm 0.54$ & $2.05 \pm 0.48$ & $2.04 \pm 0.45$ & 0.08 & 0.99 \\
\hline $\mathrm{VO}_{2} \max (\mathrm{kg} / \mathrm{ml} / \mathrm{min})$ & $33.09 \pm 4.57$ & $31.69 \pm 4.21$ & $30.73 \pm 3.78$ & $29.85 \pm 2.51$ & $32.25 \pm 5.73$ & 0.35 & 0.84 \\
\hline \multicolumn{8}{|l|}{ GROUP $\mathrm{B}_{2}$} \\
\hline \multicolumn{8}{|l|}{ CVS } \\
\hline RSBP (mmHg) & $133.00 \pm 12.06$ & $127.50 \pm 7.00$ & $125.00 \pm 7.02$ & $125.75 \pm 11.50$ & $125.00 \pm 15.19$ & 0.38 & 0.82 \\
\hline RDBP (mmHg) & $89.00 \pm 6.63$ & $83.00 \pm 12.49$ & $82.00 \pm 5.42$ & $83.00 \pm 6.22$ & $82.00 \pm 2.83$ & 0.63 & 0.65 \\
\hline RRPP (beats/min/mmHg) & $11515.00 \pm 1356.72$ & $10696.00 \pm 880.10$ & $10724.00 \pm 582.24$ & $11029.00 \pm 509.17$ & $11058.00 \pm 660.87$ & 0.60 & 0.67 \\
\hline \multicolumn{8}{|l|}{ Pulmonary } \\
\hline $\mathrm{SaO}_{2}(\%)$ & $97.50 \pm 1.73$ & $97.75 \pm 0.50$ & $97.00 \pm 0.82$ & $97.75 \pm 0.50$ & $97.25 \pm 0.96$ & 0.42 & 0.79 \\
\hline FVC (litres) & $1.62 \pm 0.67$ & $1.73 \pm 0.49$ & $1.75 \pm 0.54$ & $1.78 \pm 0.49$ & $1.77 \pm 0.53$ & 0.06 & 0.99 \\
\hline $\mathrm{VO}_{2} \max (\mathrm{kg} / \mathrm{ml} / \mathrm{min}$ & $29.37 \pm 1.60$ & $30.37 \pm 2.91$ & $29.63 \pm 2.44$ & $28.87 \pm 1.54$ & $28.24 \pm 1.57$ & 0.59 & 0.68 \\
\hline
\end{tabular}

Key: $\mathrm{RSBP}=$ Resting Systolic Blood Pressure, $\mathrm{RDBP}=$ Resting Diastolic Blood Pressure, $\mathrm{RRPP}=$ Resting Rate Pressure Product, $*=$ significant at $\mathrm{p} \leq 0.05$ 
Table 4. Comparison of changes in pulmonary variables between pre-treatment (baseline) and post-treatment $\left(12^{\text {th }}\right.$ week) of the premenopausal and postmenopausal study groups

\begin{tabular}{|c|c|c|c|c|c|}
\hline & Pulmonary Variables & $\begin{array}{l}\text { Pre-Rx } \\
\text { (Baseline) }\end{array}$ & $\begin{array}{l}\text { Post-Rx } \\
\left(12^{\text {th }} \text { Week }\right)\end{array}$ & $\mathrm{t}$-value & $\mathrm{p}$-value \\
\hline \multicolumn{6}{|c|}{ Premenopausal } \\
\hline \multirow[t]{3}{*}{ GROUP $A_{1}$} & $\mathrm{SaO}_{2}(\%)$ & $98.25 \pm 0.71$ & $98.50 \pm 0.54$ & -0.80 & 0.44 \\
\hline & FVC(litre) & $1.79 \pm 0.50$ & $2.25 \pm 0.54$ & -1.78 & 0.1 \\
\hline & $\mathrm{VO}_{2} \max (\mathrm{kg} / \mathrm{ml} / \mathrm{min})$ & $33.89 \pm 4.34$ & $38.42 \pm 4.83$ & -1.98 & 0.07 \\
\hline \multirow[t]{3}{*}{ GROUP $B_{1}$} & $\mathrm{SaO}_{2}(\%)$ & $98.75 \pm 0.50$ & $98.00 \pm 0.00$ & 1.87 & 0.09 \\
\hline & FVC(litre) & $1.88 \pm 0.49$ & $2.04 \pm 0.45$ & 0.48 & 0.65 \\
\hline & $\mathrm{VO}_{2} \max (\mathrm{kg} / \mathrm{ml} / \mathrm{min})$ & $33.09 \pm 4.57$ & $32.25 \pm 5.73$ & 0.23 & 0.83 \\
\hline \multicolumn{6}{|c|}{ Postmenopausal } \\
\hline \multirow[t]{3}{*}{ GROUP $A_{2}$} & $\mathrm{SaO}_{2}(\%)$ & $97.43 \pm 0.54$ & $98.14 \pm 0.69$ & -2.17 & $0.05 *$ \\
\hline & FVC(litre) & $1.70 \pm 0.43$ & $2.17 \pm 0.49$ & -1.90 & 0.08 \\
\hline & $\mathrm{VO}_{2} \max (\mathrm{kg} / \mathrm{ml} / \mathrm{min})$ & $33.35 \pm 2.67$ & $33.35 \pm 2.93$ & -0.00 & 1 \\
\hline \multirow[t]{3}{*}{ GROUP $B_{2}$} & $\mathrm{SaO}_{2}(\%)$ & $97.50 \pm 1.73$ & $97.25 \pm 0.96$ & 0.25 & 0.81 \\
\hline & FVC(litre) & $1.62 \pm 0.67$ & $1.77 \pm 0.53$ & -0.35 & 0.74 \\
\hline & $\mathrm{VO}_{2} \max (\mathrm{kg} / \mathrm{ml} / \mathrm{min})$ & $29.37 \pm 1.60$ & $28.24 \pm 1.57$ & 1.01 & 0.35 \\
\hline
\end{tabular}

Key: $\mathrm{SaO}_{2}$ Arterial Oxyhaemoglobin Saturation, $\mathrm{FVC}=$ Forced Vital Capacity, $\mathrm{VO}_{2} \mathrm{max}=\mathrm{Maximal}$ Oxygen Uptake, $*=$ significant at $\mathrm{p} \leq 0.05$

Table 5. Comparison of changes in cardiovascular / pulmonary variables of premenopausal BCS with that of postmenopausal BCS and the cumulative mean changes in the variables of different groups at the $12^{\text {th }}$ week

\begin{tabular}{|c|c|c|c|c|c|c|}
\hline GROUP & CVS/Pulmonary Variables & $\begin{array}{l}\text { Premenopausal Mean } \\
\text { Changes }\end{array}$ & $\begin{array}{l}\text { Postmenopausal Mean } \\
\text { Changes }\end{array}$ & t-value & p-value & $\begin{array}{l}\text { Cumulative Mean } \\
\text { Change }\end{array}$ \\
\hline \multirow[t]{3}{*}{ A } & $\mathrm{RSBP}(\mathrm{mmHg})$ & 19.25 & 17.43 & 0.39 & 0.71 & 36.68 \\
\hline & $\mathrm{RDBP}(\mathrm{mmHg})$ & 11.75 & 14.00 & -0.61 & 0.55 & 25.75 \\
\hline & $\mathrm{RRPP}($ beat/min/mmHg) & 2437.00 & 1357.71 & 2.19 & $0.05 *$ & 3794.71 \\
\hline \multirow[t]{3}{*}{ B } & $\mathrm{RSBP}(\mathrm{mmHg})$ & 0.00 & 8.00 & -0.26 & 0.81 & 8 \\
\hline & $\mathrm{RDBP}(\mathrm{mmHg})$ & 2.00 & 7.00 & -1.73 & 0.13 & 9 \\
\hline & $\mathrm{RRPP}($ beat $/ \mathrm{min} / \mathrm{mmHg})$ & -173.00 & 457.00 & 0.22 & 0.84 & 284 \\
\hline \multirow[t]{3}{*}{ A } & $\mathrm{SaO}_{2}(\%)$ & -0.25 & -0.71 & -1.89 & 0.08 & -0.96 \\
\hline & FVC(litre) & -0.46 & -0.46 & -0.04 & 0.97 & -0.92 \\
\hline & $\mathrm{VO}_{2} \max (\mathrm{kg} / \mathrm{ml} / \mathrm{min})$ & -4.54 & -0.01 & 2.52 & $0.03 *$ & -4.55 \\
\hline \multirow[t]{3}{*}{ B } & $\mathrm{SaO}_{2}(\%)$ & 0.75 & 0.25 & -1.85 & 0.11 & 1 \\
\hline & FVC(litre) & -0.16 & -0.15 & 0.15 & 0.88 & -0.31 \\
\hline & $\mathrm{VO}_{2} \max (\mathrm{kg} / \mathrm{ml} / \mathrm{min})$ & 0.84 & 1.14 & 0.77 & 0.47 & 1.98 \\
\hline
\end{tabular}

Key: $\mathrm{RSBP}=$ Resting Systolic Blood Pressure, $\mathrm{RDBP}=$ Resting Diastolic Blood Pressure, RRPP $=$ Resting Rate Pressure Product, SaO ${ }_{2}$ Arterial Oxyhaemoglobin Saturation, FVC $=$ Forced Vital Capacity, $\mathrm{VO}_{2} \mathrm{max}=$ Maximal Oxygen Uptake, BCS $=$ Breast cancer survivors

Improvements in the $\mathrm{VO}_{2} \max$ (a pulmonary variable) of Group A were more pronounced in the premenopausal BC survivors than in postmenopausal BC survivors. There was a significant difference in the mean changes in $\mathrm{VO}_{2} \mathrm{max}$ $\left(p=0.03^{*}\right)$ between premenopausal and postmenopausal BC survivors. The cumulative mean changes in all the pulmonary variables were more pronounced in Group A than in Group B (table 5).

\section{DISCUSSION}

The significant differences observed in two of the cardiovascular parameters (RSBP and RRPP) of Group $\mathrm{A}_{1}$ and in all the three cardiovascular parameters (RSBP, RDBP and RRPP) of Group $\mathrm{A}_{2}$ imply that aerobic exercise using the treadmill had significant therapeutic effects on the cardiovascular parameters of the premenopausal and postmenopausal BC survivors. These significant therapeutic 
effects in RSBP occurred earlier in premenopausal BC survivors (end of $6^{\text {th }}$ week) than in postmenopausal BC survivors (end of $12^{\text {th }}$ week) while that of RRPP occurred at the same time (end of $12^{\text {th }}$ week) in the 2 groups. Significant therapeutic effect in RDBP occurred only in the postmenopausal BC survivors at the end of the $9^{\text {th }}$ week and continued to the end of the $12^{\text {th }}$ week. These significant therapeutic effects of aerobic exercise on the cardiovascular parameters of premenopausal and postmenopausal BC survivors were further buttressed by the changes in cardiovascular variables between pre-treatment and posttreatment, where all the cardiovascular parameters (RSBP, RDBP and RRPP) showed significant improvements in the 2 groups of BC survivors. These findings may be due to the fact that aerobic exercise improves myocardial circulation and metabolism which in turn protects the heart from hypoxic stress, and also enhances glycolytic capacity as reported by Pollock et al (2000). This improvement of myocardial circulation and metabolism improves the heart's oxygen supply and its contractility during a specific challenge, thus the heart rate and blood pressure are favourably lowered, so that the work of the myocardium is significantly reduced at rest and during exercise. Aerobic exercise using the treadmill brought about more significant therapeutic improvements in the RSBP and RRPP of the premenopausal $\mathrm{BC}$ survivors than the postmenopausal $\mathrm{BC}$ survivors but in RDBP, the reverse was the case.

Although there were changes in the 3 pulmonary parameters $\left(\mathrm{SaO}_{2}, \mathrm{FVC}\right.$ and $\left.\mathrm{VO}_{2} \mathrm{max}\right)$ of Groups $\mathrm{A}_{1}$ and $\mathrm{A}_{2}$, they were not statistically significant except in the comparison of $\mathrm{SaO}_{2}$ in Group $\mathrm{A}_{2}$ between pre-treatment and post-treatment. This implies that aerobic exercise using the treadmill showed signs of effecting therapeutic improvements in the pulmonary parameters of both premenopausal and postmenopausal BC survivors. The reason for this may be that the long-term effect of exercise leads to expansion of the oxygen transport system, which is reflected by the augmented capacity for maximal work (Wilmore and Costill, 2005). It results in larger lung size and vital capacity, higher blood volume and total haemoglobin, larger stroke volume, maximal oxygen uptake and arterio-venous oxygen difference. Aerobic exercise using the treadmill brought about more beneficial effect on the $\mathrm{VO}_{2} \mathrm{max}$ of the premenopausal $\mathrm{BC}$ survivors than that of the postmenopausal $\mathrm{BC}$ survivors. The reverse was the case for $\mathrm{SaO}_{2}$ while it had equal effects on the FVC of the 2 groups of BC survivors.
These findings are partly consistent with the results of previous studies that reported that moderate intensity aerobic training brought about significant improvements in the cardiopulmonary parameters of study participants (Burnham and Wilcox, 2002; Drouin, 2002; Courneya et al, 2003; Crowley, 2003). However, the findings of these studies on significant improvement in the pulmonary functions of the subjects differ slightly with that of the present study and this may be due to differences in the duration of exercise intervention. The duration of exercise intervention by Courneya et al (2003) was 15 weeks while this study was 12 weeks. Some studies combined aerobic, resistance and stretching exercises for each participant to achieve an individualized, prescriptive exercise which was carried out for 6 months (Schneider et al, 2003; Schneider et al, 2007; Hsieh et al, 2008). Schneider et al (2007) reported that moderate intensity, individualized, prescriptive exercise maintains or improves cardiovascular and pulmonary function during and after cancer treatment. Segal et al (2001) reported that low intensity aerobic exercise programme had no effects on the aerobic fitness ( $\mathrm{VO}_{2}$ peak) of $\mathrm{BC}$ patients receiving chemotherapy.

The limitation of this study was the relative small sample size due to the fact that many $\mathrm{BC}$ survivors were unwilling to participate in the study because of the side effects of chemotherapy and/or radiotherapy, in particular the cancer-related fatigue (CRF) that they were experiencing at the time of the study. Some of those who were willing to participate in the study were referred to the hospital for treatment from hospitals in other states of the country; therefore, they were unable to stay for the total duration of the study. These factors also accounted for the delay in completion of the study.

Based on the findings of this study, it is therefore recommended that progressive aerobic exercise training, prescribed and supervised by physiotherapists, should be included in the management of BC survivors in order to improve their cardiovascular fitness.

\section{Conclusion}

Aerobic exercise brought about significant therapeutic effects on selected cardiovascular parameters in female BC survivors. Improvements in the cardiovascular variables of subjects that performed progressive aerobic exercise using the treadmill were more pronounced in premenopausal BC survivors than in postmenopausal BC survivors. 


\section{Acknowledgement}

The authors acknowledge all the patients that participated in this study.

\section{Conflict of interest statement}

The authors had no conflict of interest.

\section{References}

Adebamowo C.A., Ajayi O.O. 2000. Breast cancer in Nigeria. West African Journal of Medicine 19(3):179-191.

Adesunkanmi A.R., Lawal O.O., Adelusola K.A., Durosimi M.A. 2006. The severity, outcome and challenges of breast cancer in Nigeria. Breast 15(3): 399-409.

American Cancer Society. 2012. Breast Cancer Facts and Figures Andersen L.J., Randers M.B., Westh K., Martone D., Hansen P.R., Junge A., Dvorak J., Bangsbo J., Krustrup P. 2010. Football as a treatment for hypertension in untrained 30-55year old men: a prospective randomized study. Scandinavian Journal of Medicine and Science in Sports 10.1111/j.16000838.2010.01109.

Brockstein B.E., Smiley C., Al-Sadir J., Williams S.F. 2000. Cardiac and pulmonary toxicity in patients undergoing highdose chemotherapy for lymphoma and breast cancer: Prognostic factors. Bone Marrow Transplant 25: 885-894.

Burnham T.R., Wilcox A. 2002. Effects of exercise on physiological and psychological variables in cancer survivors. Medicine and Science in Sports and Exercise 34: 1863-1867.

Calle E.E., Thun M.J., Petrelli J.M., Rodriguez C., Health C.W. 1999. Body mass index and mortality in a prospective cohort of US adults. New England Journal of Medicine 341:1097-1105.

Courneya K.S., Mackey J.R., Bell G.J., Jones L.W., Field C.J., Fairey A.S. 2003. Randomized controlled trial of exercise training in postmenopausal breast cancer survivors: Cardiopulmonary and quality of life outcomes. Journal of Clinical Oncology 21: 1660-1668.

Crowley S.A. 2003. The Effect of A Structured Exercise Programme on Fatigue, Strength, Endurance, Physical Selfefficacy, and Functional Wellness in Women with Early Stage Breast Cancer. Ann Arbor, MI: University of Michigan; 127.

Demark-Wahnefried W., Peterson B., Winer E. 2001. Changes in weight, body composition, and factors influencing energy balance among premenopausal breast cancer patients receiving adjuvant chemotherapy. Journal of Clinical Oncology 19(9): 2381-2389.

Drouin J. 2002. Aerobic exercise training effects on physical function, fatigue and mood, immune status, and oxidative stress in subjects undergoing radiation treatment for BC. Detroit: Wayne State University; 1-142.

Gianni L., Dombernowsky P., Sledge G. 2001. Cardiac function following combination therapy with paclitaxel and doxorubicin: An analysis of 657 women with advanced breast cancer. Annals of Oncology 12: 1067-1073.
Herrero F., Balmer J., San Juan AF., Foster C., Fleck S.J., Perez M., Canete S., Earnest C.P., Lucia A. 2006. Is cardiorespiratory fitness related to quality of life in survivors of breast cancer? The Journal of Strength and Conditioning Research 2006; 20(3): 535-540.

Holmes M.D., Chen W.Y., Feskanich D., Kroenke C.H., Colditz G.A. 2005. Physical activity and survival after breast cancer diagnosis. Journal of American Medical Association 293: 2479-2486.

Hsieh C.C., Sprod L.K., Hydock D.S., Carter S.D., Hayward R., Schneider C.M. 2008. Effects of a supervised exercise intervention on recovery from treatment regimens in breast cancer survivors. Oncology Nursing Forum 35(6): 909-915.

Jemal A., Bray F., Center M.M., Ferlay J., Ward E., Forman D. 2011. Global cancer statistics. Cancer Journal for Clinicians 61(2): 69-90.

Jones L.W., Haykowsky M., Peddle C.J., Joy A.A., Pituskin E.N., Tkachuk L.M., Courneya K.S., Slamon D.J., Mackey J.R. 2007. Cardiovascular risk profile of patients with HER2/neu-positive breast cancer treated with anthracyclinetaxane-containing adjuvant chemotherapy and/or trastuzumab. Cancer Epidemiology Biomarkers and Prevention 16(5): 10261031.

Jones L.W., Douglas P.S., Eves N.D., Marcom P.K., Kraus W.E., Herndon J.E., Inman B.A., Allen J.D., Peppercorn J. 2010. Rationale and design of the Exercise Intensity Trial (EXCITE): A randomized trial comparing the effects of moderate versus moderate to high-intensity aerobic training in women with operable breast cancer. BioMed Central Cancer 10: 531.

Kopelman P. 2000. Obesity as a medical problem. Nature 404: 635-643.

McInnes J., Knobf M. 2001. Weight gain and quality of life in women treated with adjuvant chemotherapy for early-stage breast cancer. Oncology Nursing Forum 28(4): 1-11.

McNeely M., Campbell K.L., Rowe B.H., Klassen T.P., Mackey J.R., Courneya K.S. 2006. Effects of exercise on breast cancer patients and survivors: A systematic review and meta-analysis. Canadian Medical Association Journal 175(1): 34-41.

Pollock M.L., Franklin B.A., Balady G.J., Chaitman B.L., Fleg J.L., Fletcher B., Limacher M., Pina I.L., Stein R.A., Williams M., Bazzarre T. 2000. Circulation 101: 828-833.

Schneider C.M., Dennehy C.A., Carter S.D. 2003. Exercise and Cancer Recovery. Champaign: Human Kinetics.

Schneider C.S., Hsieh C.C., Sprod L.K., Carter S.D., Hayward R. 2007. Effects of supervised exercise training on cardiopulmonary function and fatigue in breast cancer survivors during and after treatment. Cancer 110(4): 918-925.

Segal R., Evans W., Johnson D. 2001. Structured exercise improves physical functioning in women with stages I and II breast cancer: Results of a randomized controlled trial. Journal of Clinical Oncology 19:657-665.

Tanaka H., Monahan K.D., Seals D.R. 2001. Age-predicted maximal heart rate revisited. Journal of the American College of Cardiology 37(1): 153-156. 
Uth N., Henrik S., Kristian O., Preben K.P. 2005. Estimation of $\mathrm{VO}_{2}$ max from the ratio between HRmax, HRrest and the Heart Rate Ratio Method. European Journal of Applied Physiology 93(4): 508-509.
Wilmore J.H., Costill D.L. 2005. Physiology of Sport and Exercise, Third Edition. Human Kinetics Publishing; 56-75. 